\title{
LA JURISDICCIÓN UNIVERSAL EN MATERIA CIVIL Y EL DEBER DE REPARACIÓN POR VIOLACIONES GRAVES A LOS DERECHOS HUMANOS*
}

\author{
Mauricio Iván del TORO HUERTA**
}

RESUMEN: En los últimos años se ha incrementado el debate respecto del papel de la jurisdicción universal en materia civil como mecanismo de reparación de violaciones graves a los derechos humanos; particularmente, de los efectos de la legislación estadounidense en la materia y su influencia en el contexto mundial. El principio de jurisdicción universal en materia civil se encuentra aún en formación en el ámbito internacional y su futuro es incierto. El ejercicio de este principio por los tribunales estadounidenses es considerado, por algunos, como un instrumento último de reparación y, por otros, como un instrumento de hegemonía. El presente trabajo tiene por objeto exponer los aspectos más importantes que definen este principio a la luz de los criterios desarrollados por los tribunales estadounidenses, apuntar las críticas más relevantes e indicar algunas de sus perspectivas a futuro.

ABSTRACT: In recent years there has been increasing debate regarding the role of universal jurisdiction in civil matters as a mechanism for providing compensation for serious violations of human rights, in particular, the effects of the U. S. legislation in this area and its influence in the global context. The principle of universal jurisdiction in civil matters is still at a formative stage in the international arena and its future is uncertain. The exercise of this jurisdiction by courts in the U. S. is considered by some as an instrument of last resort for compensation and by others as an instrument of hegemony. This article is intended to explain the most important elements defining this principle in the light of the criteria developed by courts in the U. S., to note the most important criticisms and to indicate some perspectives for the future.

RÉSUMÉ: Les dernières années ont vu s'intensifier le débat quant au rôle de la juridiction universelle en matière civile comme mécanisme de réparation des violations graves des droits de l'homme; en particulier, les effets de la législation américaine en la matière et leur influence sur le contexte mondial. Le principe de juridiction universelle en matière civile est toujours en formation dans le domaine international et son avenir est incertain. L'exercice de ce principe par les tribunaux américains est considéré par quelques uns comme un instrument final de réparation et, par d'autres, comme un instrument d'hégémonie. Le présent travail expose les aspects les plus importants qui définissent ce principe, à la lumière des critères développés par les tribunaux américains, en en faisant des critiques et en envisageant des perspectives.

* El presente trabajo es una ampliación de la ponencia presentada en el Congreso Internacional de Derecho Internacional de los Derechos Humanos realizado del 23 al 26 de mayo de 2006, en el Instituto de Investigaciones Jurídicas de la UNAM.

** Profesor de derecho internacional público de la Facultad de Derecho en la UNAM. 
SUMARIO: I. Introducción. II. Aspectos generales del principio de jurisdicción universal. III. El principio de jurisdicción universal en materia penal. IV. El principio de jurisdicción universal en materia civil. V. El derecho a la reparación por violaciones graves a los derechos humanos. VI. La experiencia estadounidense a partir de la Ley sobre Indemnización Civil por Daños Extracontractuales causados a Extranjeros. VII. Comentario final. Jurisdicción civil e inmunidad de jurisdicción.

\section{INTRODUCCIÓN}

En la actualidad, la gran mayoría de las muchas y graves violaciones manifiestas a los derechos humanos quedan en la impunidad y sus víctimas, las más de las veces, en el anonimato y, por ende, en el completo olvido. Aquellas que han logrado acceder a los tribunales de justicia se encuentran muchas veces con obstáculos procesales insalvables, como la prescripción o la inmunidad de jurisdicción, las menos han podido ver tras las rejas a quienes alguna vez las torturaron o a quienes ejecutaron o desaparecieron a alguno de sus seres más cercanos; muy, muy pocas han logrado, además, una adecuada reparación para tales crímenes; todas han visto trasformado dramáticamente su proyecto de vida.

En los últimos años dentro del contexto del derecho internacional se ha incrementado el debate respecto del papel de la jurisdicción universal en materia civil como mecanismo de reparación de violaciones graves a los derechos humanos. Particularmente, de los efectos de la legislación estadounidense en la materia y su influencia en el contexto mundial. ${ }^{1} \mathrm{El}$ principio de jurisdicción universal que goza de amplio y creciente reconocimiento en materia penal (aunque su ejercicio resulte siempre polémico) no tiene el mismo nivel de consenso respecto de la materia civil y, en ocasiones, se cuestiona la aplicación de este principio como mecanismo

1 Entre los artículos de reciente aparición véase Kammimga, M., "Universal Civil Jurisdiction: Is It Legal? Is It Desirable?”, 99 Am. Soc'y Int'l L. Proc. (2005), pp. 123-125; Donovan, Donald Francis y Roberts, Anthea, "The Emerging Recognition of Universal Civil Jurisdiction", 100 Am. J. Int'L. (2006), pp. 142-164; Nolte, Georg, "Universal Jurisdiction in the Area of Private Law-The Alien Tort Claim Act" y Flauss, Jean-François, "Compétence civile universelle et droit international général", en Tomuschat, Christian y Thouvenin, Jean-Marc (eds.) The Fundamental Rules of International Legal Order. Jus cogens and Obligations Erga Omnes, Leiden-Boston, Martinus Nijhoff Publishers, 2006, pp. 373-383 y 385-415 (respectivamente). 
efectivo para la reparación de las violaciones graves a los derechos humanos, pues si bien es considerado como un instrumento último de reparación, es visto también como un instrumento de hegemonía estadounidense.

El ejercicio del principio de jurisdicción universal en materia civil se encuentra aún en formación en el ámbito internacional y su futuro es incierto. El presente trabajo tiene por objeto exponer de manera general algunos de los aspectos más importantes que definen este principio a la luz de algunos de los principales criterios desarrollados por los tribunales estadounidenses, y apuntar las críticas más relevantes sobre el ejercicio de la jurisdicción universal civil y sus perspectivas de futuro.

En los apartados siguientes se presentan algunos aspectos generales del principio de jurisdicción universal aplicables tanto en materia penal como civil; posteriormente se consideran los principales criterios que se han expresado para el ejercicio de la jurisdicción universal en materia penal, con el objeto de hacer una diferencia respecto de la jurisdicción civil; el tercer apartado trata los principales elementos de esta última; en el cuarto se exponen algunos de los principios relativos al deber de reparación de las violaciones graves a los derechos humanos; en el quinto apartado se exponen los principales criterios derivados de la legislación estadounidense sobre indemnización por daños a extranjeros y, finalmente, se concluye con un comentario final sobre algunos temas relacionados con el impacto del ejercicio de la jurisdicción universal civil en el ámbito de las relaciones internacionales.

En conjunto, el mecanismo derivado de la legislación estadounidense ha motivado la reflexión sobre ciertas estrategias de litigio encaminadas a buscar una compensación económica para las víctimas de violaciones graves a los derechos humanos en un foro distinto al lugar de su comisión y, en eso, la legislación estadounidense ha jugado un papel muy destacado; aunque también ha sido objeto de críticas, tanto internas como externas, de sus promotores como de sus retractores, las cuales han llevado a una interpretación de dicha legislación de forma variable $\mathrm{y}$, en los últimos tiempos, cada vez más restrictiva. La experiencia estadounidense es ilustrativa respecto del papel de los tribunales nacionales frente a la protección de los derechos humanos y sobre la falta de mecanismos efectivos de reparación de las violaciones graves a tales derechos, aspectos fundamentales en la construcción de una comunidad nacional e internacional más humana y más justa. 


\section{ASPECTOS GENERALES DEL PRINCIPIO DE JURISDICCIÓN UNIVERSAL}

La competencia judicial sobre ciertos crímenes internacionales está definida principalmente por la legislación estatal, por los tratados internacionales respectivos y, en algunos casos, también por el derecho internacional consuetudinario. En general, se reconocen cinco principios básicos de atribución de competencia: el principio de territorialidad, el principio de nacionalidad o personalidad activa, el principio de nacionalidad o personalidad pasiva, el principio de protección de intereses nacionales, y el principio de jurisdicción universal. ${ }^{2}$ De entre ellos, el principio de territorialidad tiene cierta preponderancia en la medida en que el lugar de comisión del crimen (locus delicti) es la base principal para el ejercicio de la jurisdicción estatal y, por tanto, se garantiza el principio del "juez natural".

En materia penal, por ejemplo, como señala el profesor Remiro Brotóns, "el locus delicti es la base de jurisdicción indiscutible, la primera de ellas, la preferente y recomendable: los delitos pueden y deben ser juzgados allí donde se cometen, más aún cuando los responsables y las víctimas son nacionales y residentes en el territorio". ${ }^{3}$ El ejercicio de la competencia territorial es la expresión natural del deber de justicia penal frente a la comisión de crímenes internacionales. Los jueces nacionales están obligados tanto por el derecho interno como por el derecho internacional (convencional y/o consuetudinario) a ejercer su jurisdicción sobre los crímenes contra la humanidad, genocidio o crímenes de guerra cometidos en su territorio.

Sin embargo, la competencia territorial, si bien primogénita no es exclusiva. ${ }^{4}$ Otros Estados pueden ejercer su jurisdicción respecto de los crí-

2 Cfr. Reydams, Luc, Universal Jurisdiction. International and Municipal Legal Perspectives, Oxford, Oxford University Press, 2004, pp. 21 y ss. Este autor además se refiere al principio de la bandera y al principio de representación.

3 Remiro Brotóns, Antonio, "Los crímenes de derecho internacional y su persecución judicial”, en varios autores, El derecho penal internacional, Escuela Judicial-Consejo General del Poder Judicial, 2001, t. VII, p. 74.

4 Ya la Corte Permanente de Justicia Internacional en el asunto Lotus (1927) señaló que si bien es verdad que en todos los sistemas legales es fundamental el carácter territorial del derecho penal, no es menos cierto que todos, o casi todos, estos sistemas extienden su jurisdicción a delitos cometidos más allá del territorio del Estado. La territorialidad del derecho penal no es, en consecuencia, un principio absoluto del 
menes internacionales sobre cualquiera de las bases ya mencionadas. De entre ellas, es el ejercicio de la jurisdicción universal el que más ha sido destacado por la doctrina como una herramienta importante para prevenir la impunidad de los crímenes internacionales, aunque también dicho principio ha generado polémica respecto de su operatividad en el ámbito de la jurisdicción civil.

En general, el principio de jurisdicción universal supone la atribución de competencia para conocer de un asunto independientemente de la existencia de un vínculo personal o territorial con los probables responsables, las víctimas o el lugar de comisión del delito, o de cualquier otro vínculo con el Estado que ejerce jurisdicción. ${ }^{5} \mathrm{El}$ principio responde a la naturaleza de la conducta, esto es, a la comisión de un crimen internacional que por su naturaleza concierne a la comunidad internacional en su conjunto y que autoriza a los jueces nacionales a actuar como agentes del orden internacional, en razón del principio del "desdoblamiento funcional" (dédoublement fonctionnel). ${ }^{6}$

En este sentido, con base en el principio de jurisdicción universal, los tribunales nacionales tienen competencia para conocer de aquellas violaciones graves a los derechos humanos cometidas fuera del territorio del Estado del foro por personas de nacionalidad diferente y respecto de víctimas también de nacionalidad diferente. Este principio de naturaleza facultativa se aplica tanto en materia penal como civil aunque con diferencias importantes y en contextos diferentes. Esta diferencia entre la ju-

derecho internacional y de ningún modo coincide con la soberanía territorial. En palabras de la corte: "Though it is true that in all systems of law the principle of territorial character of criminal law is fundamental, it is equally true that all or nearly all these systems of law extend their action to offences committed outside the territory of the State which adopts them, and they do so in ways which vary from State to State. The territoriality or criminal law, therefore, is not an absolute principle of international law and by no means coincides with territorial sovereignty'. CPJI, The Case of S.S. 'Lotus', Judgment núm. 9, 7 de septiembre de 1927, Collection of Judgments, series A, núm. 10, p. 20.

5 Cfr. Bassiouni, M. Cherif, "The History of Universal Jurisdiction and its Place in International Law" y Butler, A. Hays, "The Growing Support for Universal Jurisdiction in National Legislation", en Macedo, Stephen (ed.), Universal Jurisdiction and the Prosecution of Serious Crimes under International Law, Philadelphia, University of Pennsylvania Press, 2004, pp. 40-63 y 67-76 (respectivamente); asimismo, Benavides, Luis, "The Universal Jurisdiction Principle: Nature and Scope", Anuario Mexicano de Derecho Internacional, vol. I, 2001, pp. 19-96.

6 Cfr. Cassese, Antonio, "Remarks on Scelle's Theory of 'Role Splitting' (dédoublement fonctionnel) in International Law”, IEJIL, 1990, pp. 210-231. 
risdicción universal en materia penal respecto de la civil se evidenció en los trabajos preparatorios del Instituto de Derecho Internacional (IDI) al analizar el tema de la jurisdicción universal respecto del crimen de genocidio, los crímenes contra la humanidad y los crímenes de guerra. Ahí se consideró que la jurisdicción universal en materia civil no guardaba una relación necesaria con la jurisdicción universal penal y se decidió que los trabajos del instituto se enfocaran exclusivamente al ámbito penal. ${ }^{7}$

\section{EL PRINCIPIO DE JURISDICCIÓN UNIVERSAL}

EN MATERIA PENAL

El principio de jurisdicción universal en materia penal tiene su base principal en el derecho internacional general (consuetudinario), ${ }^{8}$ responde a la gravedad de los delitos (crímenes internacionales) y a la especial naturaleza de las normas que se consideran han sido infringidas (erga omnes). Normalmente se distingue entre la jurisdicción universal condicionada (conditional universal jurisdiction) que requiere para su ejercicio la presencia del indiciado en el territorio del Estado que la ejerce ( $f_{o}-$ rum deprehensionis), y la jurisdicción universal pura o absoluta (absolute universal jurisdiction), que no está condicionada a la presencia del incul-

7 En su exposición preliminar, el relator Christian Tomuschat formuló a los miembros del IDI, entre otros cuestionamientos, el relativo a si en el estudio del tema de la jurisdicción universal en materia penal debería incluirse las cuestiones relacionadas con la reparación civil, en el sentido desarrollado por la legislación estadounidense. Al respecto, los diferentes miembros de la 17a. Comisión del Instituto (en particular, Yoram Dinstein, Francisco Orrego, Mohamed Bennouna, Lucius Caflisch, Nisuke Ando, Santiago Torres, Jean Salmon, Benedetto Conforti, Christos L. Rozakis, Antonio Cassese, Roy $\mathrm{S}$. Lee) consideraron que la cuestión relativa a la reparación civil no debería ser tratada conjuntamente con la jurisdicción universal penal. Cfr. Institute of International Law, Yearbook, vol. 71, part I, session of Krakow, 2005, first part, preparatory work, pp. 213 y ss.

8 Algunos tratados establecen la obligación de enjuiciar o extraditar (aut dedere aut iudicare) ciertos crímenes internacionales a los que el derecho internacional general faculta también su enjuiciamiento sobre la base del ejercicio de la jurisdicción universal (por ejemplo, Convención contra la Tortura, Convención contra el Genocidio o los Convenios de Ginebra sobre Derecho Humanitario), en este sentido, se está en presencia de una especie de jurisdicción universal condicionada de carácter convencional. Sin embargo, existen diferencias entre la doble obligación de enjuiciar o extraditar al sujeto activo de la conducta criminal y la facultad de enjuiciarlo sobre la base del principio de jurisdicción universal; la primera impone una obligación, mientras la segunda sólo faculta a los Estados a ejercerla, salvo que exista una obligación expresa en el derecho interno. Cfr. Benavides, Luis, op. cit., nota 5, pp. 32 y ss. 
pado e incluso puede ejercerse (en su expresión más general y también más cuestionable) en ausencia del acusado (in absentia). ${ }^{9}$

En este sentido, el IDI en su resolución denominada Universal Criminal Jurisdiction with Regard to the Crime of Genocide, Crimes Against Humanity and War Crimes, adoptada el 26 de agosto de 2005, en su sesión de Cracovia, consideró:

1. Universal jurisdiction in criminal matters, as an additional ground of jurisdiction, jeans the competence of a State to prosecute alleged offenders and to punish them if convicted, irrespective of the place of commission of the crime and regardless of any link of active or passive nationality, or other grounds of jurisdiction recognized by international law.

2. Universal jurisdiction is primarily based on customary international law. It can also be established under a multilateral treaty in the relations between the contracting parties, in particular by virtue of clauses which provide that a State party in the territory of which an alleged offender is found shall either extradite or try that person.

En general se reconoce que la comisión de los siguientes crímenes internacionales autorizan o facultan el ejercicio de la jurisdicción universal: el crimen de genocidio, los crímenes contra la humanidad, los crímenes de guerra, el crimen de esclavitud y la piratería. Además, sobre las condiciones de ejercicio de la jurisdicción universal, generalmente han de considerarse algunos otros aspectos relacionados tanto con la naturaleza del crimen, como con la conducta del Estado que ejerce la jurisdicción, las posibles limitaciones o restricciones procesales a su ejercicio, así como con los principios que deben guiar el proceso interno.

A continuación se hace una apretada síntesis de algunos de los principales criterios que se han considerado en diferentes documentos elabo-

9 Cfr. Cassese, Antonio, International Criminal Law, Oxford, Oxford University Press, 2003, pp. 284 y ss. La mayoría de los Estados que reconocen la jurisdicción universal en sus legislaciones, condicionan su ejercicio a la presencia del inculpado o establecen algún otro vínculo con el Estado (jurisdicción cuasi-universal), entre ellos, por ejemplo, Austria, Alemania, Suiza, así lo han interpretado también los tribunales franceses respecto de los crímenes de guerra para fines de la implementación del Estatuto del Tribunal Penal Internacional para la Antigua Yugoslavia. Los juicios in absentia son incompatibles con las normas internacionales sobre el debido proceso, aunque en algunos casos se permite iniciar la investigación del caso y requerir la extradición del inculpado (España). Para una revisión de la práctica europea véase: Human Rights Watch, Universal Jurisdiction in Europe. The State of the Art, vol. 18, núm. 5(D), junio de 2006. 
rados por distintas organizaciones e instituciones internacionales que, dada su importancia, han de considerarse al momento de reflexionar sobre este tema, sin que ello suponga que tales criterios son obligatorios, algunos de los cuales no cuentan con un reconocimiento general de los Estados. ${ }^{10}$ En conjunto, podemos decir que:

a) Reconociendo que el ejercicio de la jurisdicción universal encuentra su fundamento principalmente en el derecho internacional consuetudinario, todos los Estados están facultados para ejercerla, siempre que concurran los siguientes elementos: que se ejerza sobre determinados crímenes internacionales (por ejemplo, genocidio, crímenes de guerra y crímenes contra la humanidad); que su ejercicio se haga de buena fe, sin fines políticos, y en él se observen las normas del debido proceso nacional e internacionalmente reconocidas; y que el juicio se lleve en presencia del acusado, no así, necesariamente, el inicio de la investigación (principio 1.5., Proyecto Princeton; artículo 4, Res. de Cracovia, IDI; Recoms. 1 y 2, ILA; principios 3, 5, 6, 8 AFLA).

b) Los Estados deben garantizar que sus tribunales nacionales y ordinarios puedan ejercer la jurisdicción universal en nombre de la comunidad internacional si dentro de su territorio o jurisdicción se encuentra una persona sospechosa de haber cometido tales crímenes o de solicitar, en su caso, su extradición de acuerdo con las leyes y los procedimientos correspondientes (principio 1, AI; principio 1.1. Proyecto Princeton; artículo 3.b, Res. de Cracovia, IDI; Recomen. 3, ILA; principio 3, AFLA).

10 En especial se consideran los documentos elaborados por Amnistía Internacional (AI), el Proyecto Princeton sobre Jurisdicción Universal, el IDI, la International Law Association (ILA) y la African Legal Aid (AFLA). Véase Amnesty International, Universal Jurisdiction: 14 Principles on the Effective Exercise of Universal Jurisdiction, AI INDEX: IOR 53/01/1999, mayo de 1999, en http:/www.amnesty.org. Los principios del Proyecto Princeton pueden consultarse en http://www.law.uc.edu/morgan/newsdir/ univjuris.html; la resolución del IDI, Universal criminal jurisdiction with regard to the crime of genocide, crimes against humanity and war crimes de 26 de agosto de 2005 está disponible en http://www.idi-iil.org. Las recomendaciones de la ILA pueden consultarse en ILA-Committee on International Human Rights Law and Practice, Final Report on the Exercise of Universal Jurisdiction in Respect of Gross Human Rights Offences, 2000 Conference Report (London), disponible en http://www.ila-hq.org. Los principios elaborados por la AFLA están desarrollados en The Cairo-Arusha Principles on Universal Jurisdiction in Respect of Gross Human Rights Offences: an African Perspective, disponible en http://www.kituochakatiba.co.ug/cairo-arusha.htm. 
c) Los jueces nacionales deberán ejercer la jurisdicción universal sobre los crímenes internacionales aun en ausencia de legislación nacional específica (principio 3, Proyecto Princeton; principio 5, AFLA).

d) Los Estados que se encuentren en custodia de un acusado, antes de iniciar un juicio sobre la base exclusiva de la jurisdicción universal, harán lo posible por preguntar al Estado donde el crimen fue cometido o al Estado de la nacionalidad de las víctimas, si está preparado para perseguir tales crímenes, al menos que tales Estados se muestren manifiestamente incapaces o no deseen llevar a cabo el juicio; además los Estados de la custodia deberán tomar en consideración la competencia de los tribunales penales internacionales, en especial de la Corte Penal Internacional. En el mismo sentido, el Estado de la custodia deberá considerar, de acuerdo con el derecho aplicable, aquellas solicitudes de extradición de otros Estados con vínculos más significativos con la comisión del crimen (vínculos de territorialidad o nacionalidad activa o pasiva) cuando se demuestre su capacidad y deseo de procesar al acusado (artículo 3.c y d., Res. de Cracovia, IDI; principio 19, AFLA).

e) En la consideración respecto a la posible existencia de jurisdicciones concurrentes, los jueces del Estado de la custodia podrán considerar, entre otras, las siguientes circunstancias: a) Las obligaciones derivadas de tratados multilaterales o bilaterales; b) El lugar de comisión del delito; c) La relación de nacionalidad del supuesto autor del delito con el Estado requirente; d) La relación de nacionalidad de la víctima con el Estado requirente; e) Cualquier otra relación entre el Estado requirente y el supuesto autor, el delito o la víctima; f) La posibilidad, buena fe y eficacia del juicio penal en el Estado requirente; $g$ ) La garantía de justicia e imparcialidad de los juicios en el Estado peticionante; $h$ ) La conveniencia para las partes y testigos, así como también la disponibilidad de pruebas en el estado requirente; e $i$ ) Los intereses de la justicia (principio 8, Proyecto Princeton).

f) Las autoridades correspondientes deberán estar en posibilidad de actuar de oficio (principio, $8 \mathrm{AI}$ ) y, en general, los Estados deberán cooperar plenamente y de buena fe en la investigación y en el procedimiento que se realice en otros Estados bajo el ejercicio de la jurisdicción universal (principio 13, AI; principios 1.5 y 4 Proyecto Princeton; artículo 5, Res. de Cracovia, IDI; Recomendación 6, ILA principio 10, AFLA). Para ello, los Estados deberán garantizar que los jueces, fiscales, investigadores y abogados defensores reciban la formación y capacitación pertinente 
en las normas relevantes del derecho internacional de los derechos humanos, el derecho internacional humanitario y el derecho penal internacional (principio 14, AI).

g) Los Estados deberán garantizar que la legislación interna otorgue plena competencia a los tribunales nacionales respecto de toda persona acusada de tales crímenes, independientemente del cargo oficial de esa persona al momento de cometer dichas conductas o en cualquier otro momento posterior (principios 1 y 2, AI; principio 11, Proyecto Princeton; Recomendación 4, ILA) Además, respecto de los crímenes mencionados no se aplicarán amnistías, plazos de prescripción, ni ningún otra forma que limite la competencia de los jueces nacionales. Por su propia naturaleza tales crímenes se consideran imprescriptibles. Además, las autoridades estatales garantizarán que no se apliquen eximentes de responsabilidad, tales como las órdenes superiores, la coacción o el estado de necesidad (principios 2-6, AI; principios 5- 7, Proyecto Princeton; Recomendación 5, ILA; principios 14 y 15, AFLA).

h) En todo juicio, seguido en ejercicio del principio de jurisdicción universal, deberán respetarse las normas internacionales relativas al debido proceso, y en consecuencia los fiscales y jueces que participen a lo largo del proceso deberán ser independientes e imparciales, y basar sus resoluciones en consideraciones de naturaleza exclusivamente jurídica y no en cuestiones políticas (principio 7, AI; principio 1.3. Proyecto Princeton; artículo 4, Res. de Cracovia, IDI, Recomen. 9, ILA; principio 11, AFLA).

i) Las autoridades nacionales deberán velar porque se respete el principio non bis in idem y que el acusado no sea sometido a múltiples juicios, siempre que los juicios anteriores hayan sido conducidos de buena fe y de acuerdo a las normas y estándares internacionales, de tal forma que no se reconocerán los juicios fraudulentos realizados en otra jurisdicción nacional (principio 9, Proyecto Princeton).

j) Los juicios deberán ser públicos y, si es posible, con asistencia de observadores internacionales (principio 10, AI). Además, los acusados deberán gozar de todas las garantías reconocidas internacionalmente durante el proceso, para que su juicio sea justo (principio 9, AI; principio 1.4. Proyecto Princeton).

k) No se impondrá al condenado la pena de muerte, ni otras penas crueles, inhumanas o degradantes, y un Estado requerido podrá rehusar la extradición basada en el principio de jurisdicción universal si existe la 
posibilidad de la imposición de tales penas en el Estado requirente (principio 12, AI; principio 10, Proyecto Princeton).

1) Los jueces nacionales, por su parte, deberán guiar su conducta de conformidad con las normas internacionales del debido proceso, teniendo en cuenta los intereses especiales de las víctimas, de los testigos y de sus familias, y ordenar la reparación debida a las víctimas considerando la gravedad de los crímenes (principio 11, AI; principio 1.4. Proyecto Princeton; principio 12, AFLA).

m) Los jueces nacionales deberán interpretar la legislación nacional de manera compatible con los principios que rigen la jurisdicción universal (principio 13, Proyecto Princeton).

En conjunto, la jurisdicción universal en el ámbito del derecho penal es un mecanismo efectivo de carácter extraordinario para evitar que ciertas conductas consideradas por su gravedad como crímenes de derecho internacional queden impunes. En este sentido, con el ejercicio de dicha jurisdicción se busca sancionar penalmente a los individuos responsables de tales conductas, ${ }^{11}$ es una jurisdicción principalmente de carácter punitivo. Por otra parte, en el ámbito de la justicia civil, la jurisdicción universal funciona principalmente como un mecanismo de reparación de las violaciones graves a los derechos humanos o a algunos de ellos y no como un mecanismo de represión penal. Si bien la base de la jurisdicción es generalmente la misma, lo cierto es que en la práctica ambas formas de jurisdicción universal (penal y civil) se han mantenido como dos formas diferentes de ejercicio extraterritorial de la jurisdicción estatal, aunque se estima que debiera buscarse la adecuada complementariedad entre ambas.

\section{EL PRINCIPIO DE JURISDICCIÓN UNIVERSAL EN MATERIA CIVIL}

La jurisdicción universal en materia civil supone que los tribunales nacionales están facultados para conocer de violaciones a los derechos internacionalmente reconocidos sin que para ello se requiera algún vínculo con el Estado del foro, salvo la presencia física del demandado (jurisdicción universal condicionada) o la existencia de una base de jurisdicción personal mínima que garantice un debido proceso (minimum

11 Sólo en el documento de la AFLA se considera que el principio de jurisdicción universal debe aplicarse tanto respecto de actos de personas individuales como de otras entidades (principio 1). 
contacts doctrine). ${ }^{12} \mathrm{Si}$ bien en la mayoría de los países existen recursos judiciales por agravios sufridos en materia de responsabilidad civil extracontractual, tratándose de violaciones graves a los derechos humanos generalmente existe un vínculo o conexión necesaria entre la responsabilidad por daños y la responsabilidad penal del inculpado y, en su caso, la responsabilidad subsidiaria o solidaria del Estado. En cualquier caso, la base material de la demanda es la legislación nacional. Por el contrario, la jurisdicción universal en materia civil versa sobre violaciones al derecho internacional y no tiene una conexión necesaria con la responsabilidad penal internacional. En este sentido, la jurisdicción universal en materia civil no está relacionada propiamente con el deber de justicia penal relativo a la investigación y sanción de los crímenes internacionales ni con el ejercicio de la jurisdicción universal en materia penal, aunque sí se encuentra relacionada con el derecho de las víctimas a una adecuada reparación y con el derecho a la verdad.

El ejemplo más significativo (prácticamente el único) de ejercicio de esta jurisdicción civil lo representa la legislación de Estados Unidos de América. ${ }^{13}$ La ley estadounidense sobre indemnización civil por daños extracontractuales causados a extranjeros, denominada Alien Tort Claims Act, de 1789 (ATCA o ATS), otorga competencia a las cortes federales de distrito para conocer de casos en que un extranjero reclame violaciones al derecho internacional o a los tratados internacionales en que Estados Unidos de América es parte. ${ }^{14}$ Asimismo, la Torture Victim Protection Act de 1992, autoriza a cualquier individuo, nacional o extranjero, para reclamar civilmente la comisión de actos de tortura o ejecuciones extrajudiciales, siempre y cuando no hayan tenido un adecuado remedio en el lugar de comisión de tales acciones. ${ }^{15}$

12 En opinión de Menno Kammimga: "Universal civil jurisdiction or universal tort jurisdiction may be defined as the principle under which civil proceedings may be brought in a domestic court irrespective of the location of the unlawful conduct and irrespective of the nationality of the perpetrator or the victim, on the grounds that the unlawful conduct is a matter of international concern". Kammimga, M., op. cit., nota 1, pp. 123-125.

13 Cfr. Moulier, Isabelle, "Observations sur l'Alien Tort Claims Act et ses Implications Internationales ”, Annuaire Français de Droit International, XLIX, 2003, pp. 129-164.

14 Textualmente la ATCA establece: "The district courts shall have original jurisdiction of any civil action by an alien for a tort only, committed in violation of the law of nations or a treaty of the United Status". 28 U.S.C. $\$ 1350$.

15 Cfr. Lo, Ying-Jen, Human Rights Litigation Promoting International Law in U.S. Courts, Nueva York, LFB Scholarly Publishing LLC, 2005. 
En las últimas décadas cientos de denuncias civiles han sido interpuestas ante los tribunales estadounidenses a efecto de determinar la responsabilidad civil de extranjeros acusados de violaciones graves a los derechos humanos internacionalmente reconocidos. ${ }^{16}$ Sin embargo, a diferencia del amplio consenso en torno al principio de jurisdicción universal en materia penal, el ejercicio de la jurisdicción universal en materia civil no cuenta con reconocido consenso internacional y existen ciertas dudas sobre su aplicación y pertinencia, ${ }^{17}$ principalmente cuando se pretende desconocer el principio de inmunidad de jurisdicción de los Estados y la correspondiente inmunidad de ejecución, bajo el argumento de que las inmunidades de jurisdicción no deben aplicarse respecto de actos que violen gravemente normas fundamentales de derecho internacional (delicia juris gentium). ${ }^{18}$

16 Orentlicher, Diane, "The Future of Universal Jurisdiction in the New Architecture of Transnational Justice", en Macedo, Stephen (ed.), op. cit., nota 5, p. 227.

17 Cfr. Kammimga, M., op. cit., nota 1, p. 126. Al respecto, también los jueces Higgins, Kooijmans y Buergenthal, consideraron en su voto separado en el caso sobre la orden de arrestro (Arrest Warrant Case), que el ejercicio de los poderes concedidos por la ATCA a los tribunales federales estadounidenses no goza de reconocimiento ni aprobación general por parte de los otros Estados (has not attracted the approbation of State generally). CIJ, Case concerning the arrest warrant of 11 April 2000 (Democratic Republic of the Congo vs. Belgium), 14 de febrero de 2002, núm. 121. Joint Separate opinion of judges Higgins, Kooijmans and Buergenthal, párr. 48. Disponible en http://www.icj-cij.org.

18 La Convención de las Naciones Unidas sobre las Inmunidades Jurisdiccionales de los Estados y de sus Bienes, adoptada por la Asamblea General de Naciones Unidas mediante su resolución 59/38 de 2 de diciembre de 2004, considera que "todo Estado goza, para sí y sus bienes, de inmunidad de jurisdicción ante los tribunales de otro Estado" (artículo 5). Sin embargo, tratándose de transacciones mercantiles entre los Estados y una persona natural o jurídica extranjera, los primeros no pueden hacer valer su inmunidad de jurisdicción, salvo acuerdo en contrario (artículo 7). Lo mismo es aplicable, en los términos de la Convención y salvo acuerdo en contrario de las partes en acciones de indemnización pecuniaria por lesiones a las personas y daños a sus bienes atribuibles a un Estado en el Estado del foro y siempre que el autor se encuentre en el territorio de ese otro Estado (artículo 12). La Convención no establece una excepción al principio de inmunidad de jurisdicción por violaciones a normas imperativas de derecho internacional o por la comisión de crímenes internacionales. Cfr. Keith Hall, Christopher, "UN Convention on State Immunity: The Need for a Human Rights Protocol" y McGregor, Lorna, "State Immunity and Jus Cogens", Int. Comp Law Q (2006) 55, pp. 411-426 y 437-446, respectivamente. Véase también Bankas, Ernest, The State Immunity Controversy in International Law. Private Suits Against Sovereign States in Domestic Courts, primavera de 2005. 
En principio, el fundamento jurídico de la jurisdicción universal en materia civil es el mismo que el enunciado para la materia penal, la posibilidad de que los Estados ejerzan su jurisdicción de forma extraterritorial respecto de ciertas conductas consideradas como crímenes internacionales. Además, en general los Estados no han rechazado el ejercicio de esta jurisdicción civil por los tribunales estadounidenses, lo que contribuye a fortalecer la presunción de legalidad de la jurisdicción universal civil en el derecho internacional. ${ }^{19}$ Para algunos existe una creciente aceptación de la necesidad de implementar esta jurisdicción ahí donde no existen otros mecanismos efectivos para garantizar la reparación debida a las víctimas de violaciones graves a los derechos humanos. ${ }^{20}$ En este sentido, la historia de la ATCA es considerada un importante aporte a la aplicación por los jueces nacionales del derecho internacional de los derechos humanos dentro del contexto estadounidense. ${ }^{21}$ Para otros, el ejercicio de esta jurisdicción está subordinado a otros principios fundamentales como el de inmunidad de jurisdicción entre Estados y, en sus aspectos procesales, entre otros, al principio del agotamiento previo de los recursos internos.

\section{EL DERECHO A LA REPARACIÓN POR VIOLACIONES GRAVES A LOS DERECHOS HUMANOS}

Es un principio básico de derecho internacional que toda violación de una obligación internacional que haya producido un daño comporta el deber de repararlo adecuadamente; ${ }^{22}$ además, el deber de reparar las vio-

19 Kammimga, M., op. cit., nota 1, p. 125.

20 Cfr. Donovan, Donald Francis y Roberts, Anthea, op. cit., nota 1, pp. 142 y ss.

21 En este sentido, se pronuncia el documento de Amicus Curiae presentado por la organización International Jurists (2004 WL 398960 U.S. S.Ct. Brief) ante la Suprema Corte de Estados Unidos de América en el caso Sosa vs. Alvarez-Machain (542 U.S. 692, 124 S. Ct. 2739) entre cuyos autores destacan Mary Robinson, Radhika Coomarswamy, John Dugard, Thomas Franck, Jochen Frowein, Richard Goldstone, Louis Henkin, Claire L'Heureux, Juan Mendez y Pedro Nikken.

22 Los artículos de la Comisión de Derecho Internacional sobre Responsabiliad Internacional del Estado, de los que la Asamblea General tomó nota en su resolución 56/83 de 28 de enero de 2002, y los señaló a la atención de los gobiernos, expresan en su artículo 31 que el Estado responsable está obligado a reparar íntegramente el perjuicio causado por el hecho internacionalmente ilícito, asímismo, el artículo 26 dispone que la reparación íntegra del perjuicio causado por el hecho internacionalmente ilícito adoptará 
laciones a los derechos humanos es parte del deber general de protección y garantía de tales derechos, que si bien está referido - en principio- a una obligación estatal, ésta se proyecta al ámbito interno a través del deber general de adecuación del derecho interno al internacional, y del consecuente deber de tipificar en la legislación nacional tales conductas, lo que repercute necesariamente en las relaciones de los individuos sujetos a la jurisdicción del Estado. ${ }^{23}$

El derecho a la reparación por violaciones a los derechos humanos supone una reparación plena y efectiva. La reparación deberá tener en cuenta las circunstancias de cada caso, y deberá ser apropiada y proporcional a la gravedad de la violación. Las formas generalmente reconocidas de reparación abarcan la restitución (restitutio in integrum), indemnización, rehabilitación, satisfacción y las garantías de no repetición.

Los principios y directrices básicos sobre el derecho de las víctimas de violaciones manifiestas de las normas internacionales de derechos humanos y de violaciones graves del derecho internacional humanitario a interponer recursos y obtener reparaciones, adoptados por las Naciones Unidas establecen como formas de reparación (dentro del principio IX, relativo a la "Reparación de los daños sufridos") las siguientes: restitución, indemnización, rehabilitación, satisfacción y garantías de no repeti-

la forma de restitución, de indemnización y de satisfacción, ya sea de manera única o combinada, y más adelante, el artículo 36 establece que el Estado resposable de un hecho internacionalmente ilícito está obligado a indemnizar el daño causado por ese hecho, y cubrirá todo daño susceptible de evaluación financiara, incluido el lucro cesante.

23 Al respecto, la Corte Interamericana de Derechos Humanos ha reiterado que "el Estado está en el deber jurídico de prevenir, razonablemente, las violaciones de los derechos humanos, de investigar seriamente con los medios a su alcance las violaciones que se hayan cometido dentro del ámbito de su jurisdicción a fin de identificar a los responsables, de imponerles las sanciones pertinentes y de asegurar a la víctima una adecuada reparación". Cfr. entre otros, Corte IDH, Caso Velásquez Rodríguez, sentencia de 29 de julio de 1988, serie C, núm. 4, párr. 162; Caso Godínez Cruz, sentencia de 20 de enero de 1989, serie C, núm. 5, párr. 174. Sobre el tema de las reparaciones ante la Corte IDH, véase, entre otros, García Ramírez, Sergio, "Las reparaciones en el Sistema Interamericano de Protección de los Derechos Humanos", en varios autores, La jurisdicción internacional, derechos humanos y la justicia penal, México, Porrúa, 2003, pp. 285-319; y Saavedra Alessandri, Pablo, "Algunas consideraciones sobre las reparaciones en la jurisprudencia de la Corte Interamericana de Derechos Humanos", en Zerbini Ribeiro, Renato et al. (coords.) Rumbos del derecho internacional de los derechos humanos. Estudios en homenaje al profesor Antônio A. Cançado Trindade, Porto Alegre, Sergio Antonio Fabris Editor, 2005, pp. 95-133. 


\section{ción. ${ }^{24}$ Los principios se refieren a cada una de estas modalidades de la siguiente forma:}

19. La restitución, siempre que sea posible, ha de devolver a la víctima a la situación anterior a la violación manifiesta de las normas internacionales de derechos humanos o la violación grave del derecho internacional humanitario. La restitución comprende, según corresponda, el restablecimiento de la libertad, el disfrute de los derechos humanos, la identidad, la vida familiar y la ciudadanía, el regreso a su lugar de residencia, la reintegración en su empleo y la devolución de sus bienes.

20. La indemnización ha de concederse, de forma apropiada y proporcional a la gravedad de la violación y a las circunstancias de cada caso, por todos los perjuicios económicamente evaluables que sean consecuencia de violaciones manifiestas de las normas internacionales de derechos humanos o violaciones graves del derecho internacional humanitario, tales como los siguientes: a) El daño físico o mental; b) La pérdida de oportunidades, en particular las de empleo, educación y prestaciones sociales; c) Los

24 Los Principios y Directrices Básicos sobre el Derecho de las Víctimas de Violaciones Manifiestas de las Normas Internacionales de Derechos Humanos y de Violaciones Graves del Derecho Internacional Humanitario a Interponer Recursos y Obtener Reparaciones fueron aprobados por la Asamblea General de Naciones Unidas mediante su resolución 60/147, de 16 de diciembre de 2005, y por la antigua Comisión de Derechos Humanos, mediante resolución 2005/35, de 20 abril de 2005. Los principios fueron elaborados a lo largo de tres rondas de reuniones consultivas durante el transcurso de 15 años y contaron en su redacción con la participación de prestigiados juristas como M. Cherif Bassiouni y Theo van Boven; así como del relator Alejandro Salinas. Sobre las labores que se han desarrollado en el seno de la antigua Comisión de Derechos Humanos de Naciones Unidas en el tema de reparaciones, véanse, entre otros documentos: Naciones Unidas; Comisión de Derechos Humanos, "Informe de la tercera reunión consultiva acerca de los principios y directrices básicos sobre el derecho de las víctimas de violaciones de las normas internacionales de derechos humanos y del derecho internacional humanitario a interponer recursos y obtener reparaciones" (Ginebra, 29 de septiembre a 1o. de octubre de 2004). Presidente-relator: señor Alejandro Salinas (chile)", Doc. E/CN.4/2005/59, de 21 de diciembre de 2004; Naciones Unidas; Comisión de Derechos Humanos, El Derecho de Restitución, Indemnización y Rehabilitación de las Víctimas de Violaciones Graves de los Derechos Humanos y las Libertades Fundamentales. Informe final del Relator Especial, Sr. M. Cherif Bassiouni, presentado en Virtud de la Resolución 1999/33 de la Comisión, Doc. E/CN.4/2000/62, de 18 de enero de 2000; y Naciones Unidas, Subcomisión de Prevención de Discriminaciones y Protección a las Minorías, Estudio Relativo al Derecho de Restitución, Indemnización y Rehabilitación a las Víctimas de Violaciones Flagrantes de los Derechos Humanos y las Libertades Fundamentales. Informe definitivo presentado por el Sr. Theo van Boven, Relator Especial, Doc. E/CN.4/Sub.2/1993/8, de 2 de julio de 1993. 
daños materiales y la pérdida de ingresos, incluido el lucro cesante; d) Los perjuicios morales; e) Los gastos de asistencia jurídica o de expertos, medicamentos y servicios médicos y servicios psicológicos y sociales.

21. La rehabilitación ha de incluir la atención médica y psicológica, así como servicios jurídicos y sociales.

22. La satisfacción ha de incluir, cuando sea pertinente y procedente, la totalidad o parte de las medidas siguientes: a) Medidas eficaces para conseguir la cesación de las violaciones continuadas; b) La verificación de los hechos y la revelación pública y completa de la verdad, en la medida en que esa revelación no provoque más daños o amenace la seguridad y los intereses de la víctima, de sus familiares, de los testigos o de personas que han intervenido para ayudar a la víctima o impedir que se produzcan nuevas violaciones; c) La búsqueda de las personas desaparecidas, de las identidades de los niños secuestrados y de los cadáveres de las personas asesinadas, y la ayuda para recuperarlos, identificarlos y volver a inhumarlos según el deseo explícito o presunto de la víctima o las prácticas culturales de su familia y comunidad; d) Una declaración oficial o decisión judicial que restablezca la dignidad, la reputación y los derechos de la víctima y de las personas estrechamente vinculadas a ella; e) Una disculpa pública que incluya el reconocimiento de los hechos y la aceptación de responsabilidades; f) La aplicación de sanciones judiciales o administrativas a los responsables de las violaciones; g) Conmemoraciones y homenajes a las víctimas; h) La inclusión de una exposición precisa de las violaciones ocurridas en la enseñanza de las normas internacionales de derechos humanos y del derecho internacional humanitario, así como en el material didáctico a todos los niveles.

23. Las garantías de no repetición han de incluir, según proceda, la totalidad o parte de las medidas siguientes, que también contribuirán a la prevención: a) El ejercicio de un control efectivo de las autoridades civiles sobre las fuerzas armadas y de seguridad; b) La garantía de que todos los procedimientos civiles y militares se ajustan a las normas internacionales relativas a las garantías procesales, la equidad y la imparcialidad; c) El fortalecimiento de la independencia del poder judicial; d) La protección de los profesionales del derecho, la salud y la asistencia sanitaria, la información y otros sectores conexos, así como de los defensores de los derechos humanos; e) La educación, de modo prioritario y permanente, de todos los sectores de la sociedad respecto de los derechos humanos y del derecho internacional humanitario y la capacitación en esta materia de los funcionarios encargados de hacer cumplir la ley, así como de las fuerzas armadas y de seguridad; f) La promoción de la observancia de los códigos de conducta y de las normas éticas, en particular las normas internacionales, por los funcionarios públicos, inclusive el personal de las fuerzas de seguri- 
dad, los establecimientos penitenciarios, los medios de información, la salud, la psicología, los servicios sociales y las fuerzas armadas, además del personal de empresas comerciales; g) La promoción de mecanismos destinados a prevenir y vigilar los conflictos sociales; h) La revisión y reforma de las leyes que contribuyan a las violaciones manifiestas de las normas internacionales de derechos humanos y a las violaciones graves del derecho humanitario o las permitan.

El objetivo de tales principios es que los mismos sean considerados por los Estados y por sus órganos al momento de enfrentar una situación de violaciones a los derechos humanos; en este sentido, la Asamblea General y la antigua Comisión de Derechos Humanos (hoy consejo), al aprobar dicho instrumento recomendaron:

Que los Estados tengan en cuenta los principios y directrices básicos, promuevan el respeto de los mismos y los señalen a la atención de los miembros de los órganos ejecutivos de gobierno, en particular los funcionarios encargados de hacer cumplir la ley y las fuerzas militares y de seguridad, los órganos legislativos, el poder judicial, las víctimas y sus representantes, los defensores y abogados de derechos humanos, los medios de comunicación y el público en general. ${ }^{25}$

El hecho de que este instrumento no sea por sí mismo obligatorio no le priva de efectos jurídicos, pues se incorpora al vasto discurso del derecho internacional, dentro del denominado soft law, con un claro valor persuasivo, que los Estados como integrantes de la comunidad internacional y con base en el principio de la buena fe deben considerar con seriedad y diligencia. ${ }^{26}$

Ahora bien, en el ámbito del derecho convencional también existen obligaciones internacionales de reparación específicas, por ejemplo, la Convención contra la Tortura y Otros Tratos o Penas Crueles, Inhumanos o Degradantes establece en su artículo 14 (1), la obligación de los Estados de velar por que su legislación "garantice a la víctima de un acto de tortura la reparación y el derecho a una indemnización justa y adecuada, incluidos los medios para su rehabilitación lo más completa posible".

25 Asamblea General, Res. 60/147 y CDH, Res. 2005/35.

26 Sobre el papel del soft law en el derecho internacional, véase Toro, Mauricio del, "El fenómeno del soft law y las nuevas perspectivas del derecho internacional", Anuario Mexicano de Derecho Internacional, México, UNAM, IIJ, núm. VI, 2006, pp. 513-549. 
Al respecto, el Tribunal Penal Internacional para la Antigua Yugoslavia, en el caso Fiscal vs. Furundzija, estimó que una de las consecuencias de que la tortura esté prohibida por una norma perentoria de derecho internacional (jus cogens) se manifiesta en la posibilidad de que las víctimas, ahí donde se les reconozca locus standi, puedan iniciar una reclamación civil por daños ante un tribunal extranjero. ${ }^{27}$

No obstante lo anterior, el deber de los Estados de establecer mecanismos de reparación civil por violaciones a normas imperativas sobre la base específica del principio de jurisdicción universal no encuentra un consenso absoluto, y por tanto no existe un deber al respecto derivado del derecho internacional. Así lo demuestra la polémica sentencia del Tribunal Europeo de Derechos Humanos (TEDH) en el caso Al-Adsani vs. Reino Unido, donde se resolvió, por una apretada mayoría de nueve votos contra ocho, que el Estado no había violado el derecho al debido proceso del señor Sulaiman Al-Adsani bajo el argumento de que en el ámbito del Convenio Europeo de Derechos Humanos el derecho al debido proceso no es absoluto y no existe un deber de establecer mecanismos de reparación civil por violaciones a los derechos humanos, incluso tratán-

27 Cfr. Asunto núm. IT-95-17/I-T, párr. 155. "The fact that torture is prohibited by a peremptory norm of international law has other effects at the inter-state and individual levels. At the inter-state level, it serves to internationally de-legitimise any legislative, administrative or judicial act authorising torture. It would be senseless to argue, on the one hand, that on account of the jus cogens value of the prohibition against torture, treaties or customary rules providing for torture would be null and void ab initio, and then be unmindful of a State say, taking national measures authorising or condoning torture or absolving its perpetrators through an amnesty law. If such a situation were to arise, the national measures, violating the general principle and any relevant treaty provision, would produce the legal effects discussed above and in addition would not be accorded international legal recognition. Proceedings could be initiated by potential victims if they had locus standi before a competent international or national judicial body with a view to asking it to hold the national measure to be internationally unlawful; or the victim could bring a civil suit for damage in a foreign court, which would therefore be asked inter alia to disregard the legal value of the national authorising act. What is even more important is that perpetrators of torture acting upon or benefiting from those national measures may nevertheless be held criminally responsible for torture, whether in a foreign State, or in their own State under a subsequent regime. In short, in spite of possible national authorisation by legislative or judicial bodies to violate the principle banning torture, individuals remain bound to comply with that principle. As the International Military Tribunal at Nuremberg put it: "individuals have international duties which transcend the national obligations of obedience imposed by the individual State "'. 
dose de normas de jus cogens, cuando tales actos son cometidos en un Estado extranjero. Al respecto el TEDH señaló: "it cannot be said that the High Contracting Party was under a duty to provide a civil remedy to the applicant in respect of torture allegedly carried out by the Kuwaiti authorities". En sus votos disidentes algunos de los jueces consideraron, entre otras cosas, que no existía un fundamento para distinguir en casos de tortura, y sobre la base del carácter de las normas de jus cogens, entre obligaciones en materia penal y civil para efecto del artículo 6 de la Convención Europea relativo al derecho a un debido proceso. ${ }^{28}$

En este caso (como en el más reciente Jones vs. Ministry of Interior Al-Mamlaka Al-Arabiya AS Saudita) ${ }^{29}$ las autoridades judiciales británicas, como lo hizo también la Suprema Corte de Justicia de Ontario, Canadá, en el caso Bouzari vs. República Islámica de Irán, ${ }^{30}$ estimaron que

28 El caso se refiere a diferentes actos de tortura cometidos en perjuicio del señor Al-Adsani en el territorio de Kuwait por agentes de dicho Estado; hechos denunciados en el Reino Unido para efecto de obtener la reparación civil del daño correspondientes y que fueron desestimados por los tribunales británicos en aplicación del principio de inmunidad de jurisdicción. El TEDH estimó que en el estado actual del derecho internacional no existe una prohibición para los Estados con el fin de pretender la inmunidad en el caso de procedimientos civiles por daños y perjuicios por actos de tortura que hubieren sido perpetrados fuera del Estado de jurisdicción, por lo que la negativa de las autoridades británicas no inflingió el derecho al debido proceso. Cfr. TEDH, Case of Al-Adsani vs. The United Kingdom, Application núm. 35763/97, Judgment, 21 de noviembre de 2001, párr. 40. Texto disponible en http://www.cmiskp.echr. coe.int. Véase también Bou Franch, Valentín, "Inmunidad del Estado y violación de normas internacionales de jus cogens: el asunto AL-Adsani contra Reino Unido", Anuario de Derecho Internacional, t. XVIII, 2002, pp. 279-303; Caplan, Lee M., "State Immunity, Human Rights and Jus Cogens: A Critique of the Normative Hierarchy Theory", 97 Am. J. Int'l L., pp. 741-781.

29 House of Lords, Jones (Respondent) vs. Ministry of Interior Al-Mamlaka Al-Arabiya AS Saudita (the Kingdom of Saudi Arabia) (Appellants), [2006] UKHL 26, 14 de junio de 2006. En el presente caso, Lord Bingham of Cornhill, destacó: "[T]here is no evidence that status have recognised or given effect to an international law obligation to exercise universal jurisdiction over claims arising from alleged breaches of peremptory norms of international law, nor is there any consensus of judicial and learned opinion that they should".

30 Cfr. Larocque, François, "Bouzari vs. Iran: Testing the Limits of State Immunity in Canadian Courts", The Canadian Yearbook of International Law, 2003, pp. 343-385. Al respecto, el Comité contra la Tortura en sus conclusiones y recomendaciones derivadas de los informes presentados por Canadá durante 2002 y 2004, destacó, entre sus motivos de preocupación, "la falta de medidas eficaces para ofrecer reparación civil a las víctimas de la tortura en todos los casos", y recomendó, entre otras cosas, que "el 
el principio de inmunidad de jurisdicción de los Estados impedía a las autoridades nacionales pronunciarse sobre hechos cometidos por agentes de un Estado extranjero, independientemente de que se alegara la comisión de actos de tortura.

Sobre la relación entre el derecho a una reparación y la inmunidad de jurisdicción se volverá más adelante, aunque es preciso señalar que si bien el derecho a una justa reparación goza de amplio consenso en el ámbito del discurso del derecho internacional, no goza de la misma eficacia en la práctica estatal cuando se ponen en juego otros principios de derecho internacional y es necesario buscar los mejores mecanismos que garanticen tanto la inmunidad de jurisdicción, ahí donde ésta es aplicable, como la lucha contra la impunidad y la debida reparación.

\section{LA EXPERIENCIA ESTADOUNIDENSE A PARTIR DE LA LEY SOBRE INDEMNIZACIÓN CIVIL POR DAÑOS EXTRACONTRACTUALES CAUSADOS A EXTRANJEROS}

Esta ley (ATCA) fue promulgada en 1789, pero por casi dos siglos no fue empleada de forma significativa y no existieron consideraciones jurisprudenciales relevantes en las cortes estadounidenses. Antes de 1980, sólo un número menor de casos merecieron la aplicación de esta ley. La situación cambió considerablemente después del conocido caso Filartiga vs. Pena-Irala (1980), en el que un ciudadano paraguayo demandó a un antiguo alto oficial de policía de la dictadura militar de Strossner en el Paraguay por actos de tortura cometidos en dicho Estado que provocaron la muerte del hijo menor de edad del demandante. En el caso, la Corte de Apelación del Segundo Circuito para efecto de establecer la competencia del tribunal con base en el derecho internacional general, equiparó en sus efectos el crimen de piratería con el de tortura al señalar que: "Among the rights universally proclaimed by all nations, as we have noted, is the rights to be free of physical torture. Indeed, for purposes of civil liability, the torturer has become like the pirate and slave trader be-

Estado parte examine su posición en el marco del artículo 14 de la Convención para Garantizar la Concesión de Indemnización mediante sus Tribunales Civiles a todas las Víctimas de la Tortura. Cfr. Conclusiones y Recomendaciones del Comité contra la Tortura: Canadá 07-07-2005. CAT/C/CR/34/CAN (Concluding Observations/Coments), disponible en http://www.unhchr.ch/. 
fore him hostis humani generis, an enemy of all mankind". En consecuencia, y considerando la opinión favorable de la administración del entonces presidente Carter, dicha corte se consideró competente y estimó que "deliberate torture perpetrated under color of official authority violates universally accepted norms of the international law of human rights". ${ }^{31}$

Desde el caso Filartiga, se han presentado numerosas demandas por actos cometidos fuera del territorio de Estados Unidos de América, en perjuicio de extranjeros, inaugurándose una nueva era jurisprudencial de la ATCA. ${ }^{32}$ Desde ese entonces, la historia de la aplicación de la ATCA ha conocido de demandas por diferentes violaciones de normas internacionales, entre ellas: tortura, genocidio, violencia sexual, crímenes de guerra, esclavitud y trabajos forzosos, apartheid, ejecuciones extrajudiciales, tratos inhumanos y degradantes, daños graves al ambiente, desapariciones forzadas. ${ }^{33}$ No todas las reclamaciones han prosperado y pocas han logrado una ejecución final de la sentencia, pero en conjunto han abierto una alternativa a las víctimas de ciertas violaciones graves a los derechos humanos y han hecho posible al menos una reparación económica.

La historia de la ATCA ha pasado por diferentes momentos, algunos favorables, como el criterio seguido en Filartiga, otros más restrictivos, como el sostenido en Tel-Oren vs. Libyan Arab Republic donde se negó dar curso a la demanda presentada en contra de la Organización para la Liberación de Palestina por sobrevivientes y representantes de las vícti-

31630 F.2d 876 (2d Cir. 1980), 890, texto disponible en International Law Report, vol. 77, 1988, p. 184.

32 Cfr. Lo, Ying-Jen, op. cit., nota 15, pp. 31 y ss.

33 Entre otros casos: Kadic vs. Karadzic, 70 F. 3d 232 (2d Cir. 1995); Hwang Deum Joo vs. Japan, 332 F. 3d 679 (DC Cir. 2003); Doe I vs. Islamic Salvation Front, 993 F. Supp. 3 (DDC 1998); Presbyterian Church of Sudan vs. Talisman Energy, Inc., 244 F. Supp. 2d 289 (SDNY 2003); Doe I vs. Unocal Corp, WL 359787, (9th Cir. Feb, 14, 2003); In re South African Apartheid Litigation, MDL No. 1499 (SDNY 2004, pending litigation); Paul vs. Avril, 812 F. Supp. 207, 901 F. Supp. 330 (1994); Xuncax vs. Gramajo, 886 F Supp. 162 (D. Mass, 1995); Flores vs. S. Peru Copper Corp., 343 F. 3d 140 (2d Cir. 2003); Bano vs. Union Carbide Corp. 361 F. 3d 696 (2d Cir. 2004); Aguinda vs. Texaco, Inc., 303 F. 3d 470 (2d Cir. 2002); Beanal vs. Freeport-McMoran, Inc., 197 F. 3d 161 (5th Cir. 1999); Forti vs. Suarez-Mason, 672 F. Supp. 1531, 694 F. Supp. 707 (1990). 
mas de un ataque armado en contra de un autobús civil en Israel en $1978 .{ }^{34}$

En general, las reclamaciones por agravios en el contexto de la ATCA se han presentado en tres contextos: a) En aquellos casos donde se requiere cierto vínculo con el Estado, de tal forma que las personas privadas que se considera han cometido los agravios mantengan algún vínculo con el Estado con el fin de que sus actividades puedan ser consideradas de naturaleza cuasi-oficial (principalmente tratándose de tortura), b) Casos donde, dada la naturaleza de la norma internacional que se considera ha sido vulnerada, no se requiere de un vínculo con el Estado y procede la acción en contra de las personas privadas en cuanto tales (la piratería, el genocidio o los crímenes de guerra, por ejemplo); y c) Casos donde se demanda a empresas transnacionales por haber cooperado o participado de alguna forma en la comisión de violaciones al derecho internacional por agentes estatales del Estado extranjero o haberse beneficiado de ello. ${ }^{35}$

Filartiga, sería quizá el caso más relevante en el primer contexto. En el segundo, el caso líder en la materia es el caso Kadic vs. Karadzic, donde se demandó al líder serbio-bosnio Radovan Karadzic, "presidente" de la auto-proclamada República Srpska de Serbio-Bosnia (perseguido también por sus crímenes por el Tribunal Penal Internacional para la Antigua Yugoslavia) por actos de "limpieza étnica" cometidos en el territorio de Bosnia y Herzegovina, particularmente por actos de genocidio, violación, prostitución forzada, embarazos forzosos, tortura y otros tratos crueles, inhumanos y degradantes; asalto y maltrato; y ejecuciones sumarias. En un principio la Corte de Distrito había rechazado la demanda en tanto que la autoridad Serbio-Bosnia era un actor no-estatal y por tanto

34726 F. 2d. 774, 801-05 (1984), International Law Report, vol. 77, 1988, pp. 193 y ss. Cfr. D’Amato, Anthony, "What Does Tel-Oren Tell Lawyers: Judge Bork's Concept of the Law of Nations Is Seriously Mistaken", 79 Am. J. Int'l L., 1985, p. 92; Lo, Ying-Jen, op. cit., nota 15.

35 Cfr. Bounngaseng, Jenny, “Adjudication of International Human Rights Claims in the European Court of Human Rights and the Inter-American Court of Human Rights: Why ATCA Suits in U.S. Courts are the Better Alternative for Claims Against American Multinational Corporations", 33 Ga. L. Int'L \& Comp. L., 2004-2005, pp. 467-496; Kastenberg, Joshua, "Enforcing Internationally Recognized Human Rights Violations under the Alien Tort Claims Act: An Analysis of the Ninth Circuit's Decision in Doe vs. Unocal Corp.”, 1 Pierce L. Rev, núm. 3-4, 2002-2003, pp. 133-180. 
no responsable civilmente en el derecho internacional, sin embargo, la Corte de Apelaciones rechazó dicho argumento y señaló: "We do not agree that the law of nations, as understood in the modern era, confines its reach to state action... [C]ertain forms of conduct violate the law of nations whether undertaken by those acting under the auspices of a state or only as private individuals". ${ }^{36}$ Entre tales conductas la corte consideró el genocidio, los crímenes de guerra y otros tratos inhumanos como la tortura y las ejecuciones extrajudiciales, puntualizando que si bien los dos primeros crímenes podrían ser cometidos tanto por agentes oficiales como por personas privadas, respecto de la tortura y las ejecuciones extrajudiciales, cuando no son cometidos en el contexto de actos de genocidio o de guerra, se consideran prohibidos por el derecho internacional, "only when [there are] committed by state officials or under color of law." La corte además no consideró conveniente aplicar la excepción de forum non conveniens, en tanto que "it seems evident that the courts of the former Yugoslavia, either in Serbia or war-torn Bosnia, are not now available to entertain plaintiffs' claims, even if circumstances concerning the location of witnesses and documents were presented that were sufficient to overcome the plaintiffs' preference for a United Status forum". ${ }^{37}$

Asimismo, la ley se ha empleado para demandar tanto a particulares como empresas. El primer caso relevante de aplicación de la ATCA contra una empresa es el caso Doe vs. Unocal Corp., ${ }^{38}$ donde la Corte del Noveno Circuito consideró la posible responsabilidad de la empresa, como actor privado, por violaciones a normas de jus cogens cometidas durante el desarrollo de sus operaciones en la extracción de gas natural en Burma. Entre tales violaciones destacan la comisión de actos de tortura, detenciones arbitrarias, violaciones, asesinatos, traslado forzoso, confiscaciones ilegales de bienes y trabajos forzosos, como nuevas formas de esclavitud (slave labor). Los abusos si bien fueron ejecutados principalmente por los militares del gobierno (Burmese State Law and Order Restoration Council, SLORC) en contra de los habitantes de la región de Tenasserim, las empresas involucradas conocieron, incitaron, apoyaron y

36 Kadic vs. Karadzic, 70 F 3d 239 (2d Cir. 1995), International Law Report, vol. 104, 1997, pp. 135 y ss. Cfr. Seiderman, Ian, Hierarchy in International Law: The Human Rights Dimension, Intersentia-Hart, Antwerpen-Geoningen-Oxford, 2001, p. 261.

37 Ibidem, p. 163.

38 Doe vs. UNOCAL Corp., 963 F. Supp. 880 (C.D. Cal 1997) y 395 F. 3d 978 (9th Cir. Filed Feb. 14, 2003). Cfr. Kastenberg, Joshua, op. cit., nota 35. 
se beneficiaron de ellos. Finalmente, después de recorrer diferentes instancias judiciales en los tribunales estadounidenses y previamente a su resolución judicial definitiva, el 13 de diciembre de 2004, la empresa anunció un arreglo con los peticionarios. ${ }^{39}$ No obstante, el hecho de que UNOCAL decidiera resolver la controversia reveló la importancia de la presentación de la demanda que, en última instancia, hizo posible el pago de una compensación a las víctimas.

Finalmente, el caso de aplicación de la ATCA más reciente e importante decidido por la Suprema Corte de Estados Unidos de América fue el caso Sosa vs. Alvarez-Machain, que si bien es cierto no es propiamente un caso de ejercicio de jurisdicción universal, permitió definir al alcance de la legislación respectiva. ${ }^{40}$ En su sentencia de 29 de junio de 2004, la Corte Suprema estableció importantes criterios que seguramente definirán el futuro del ATCA. El caso Sosa vs. Alvarez-Machain, representa un episodio más en el largo litigio iniciado con la abducción ilegal del doctor Álvarez Machain del territorio mexicano por agentes de la DEA (United States Drug Enforcement Administration) por su presunta participación en la tortura y muerte de Enrique Camarena Salazar, agente de la DEA, acaecida en territorio mexicano. Álvarez Machain fue declarado inocente por falta de prueba y a su regreso a México presentó una querella civil ante los tribunales estadounidenses por los daños sufridos en la detención ilegal cometida en México entre otros, en contra el señor Sosa - quien participó en su secuestro- por los actos de arresto y detención arbitraria en violación de la ATCA. Después de diferentes instancias el caso finalmente llegó en vía de certiorari ante la Corte Suprema de Estados Unidos de América la cual consideró, contrariamente a lo decidido por el Tribunal de Apelación, que el señor Álvarez Machain no tenía derecho a reclamar conforme al ATCA los agravios sufridos en su detención y secuestro.

39 Cfr. Dhooge, Lucien J., "The Alien Tort Claims Act and the Modern Transnational Enterprise: Deconstructing the Mythology of Judicial Activism", 35 Geo. J. Int'l $L, 2003$, pp. 25-28. Sobre este caso y otros casos relacionados con la protección del medio ambiente, véase la información disponible en http://www.earthrights.org.

40 Sosa vs. Alvarez-Machain et al., 542 U.S. 692, 124 S. Ct. 2739, International Law Report, vol. 127, 2005, pp. 769 y ss. Cfr. Fuks, Igor, "Sosa vs. Alvarez-Machain and the Future of ATCA Litigation: Examining Bonded Labor Claims and Corporate Liability", Columbia Law Journal, vol. 106, núm. 1, enero de 2006, pp. 112-143. 
En su importante fallo, el alto tribunal estadounidense consideró que la ATCA no establece un derecho o causa de acción propiamente dicha sino que sólo reconoce la jurisdicción de los tribunales federales respecto de un restringido número de violaciones al derecho internacional definidos por criterios específicos, entre ellos que la norma que se alega ha sido vulnerada y goce de acuerdo unánime similar al de aquellas conductas aludidas originalmente al expedirse el ATCA, en 1789 (por ejemplo, piratería) y en consecuencia que, entre otras cosas, goce de suficiente especificidad, universalidad y obligatoriedad como para ser considerada contraria al derecho internacional. Además, en la consideración de tal circunstancia existe un elemento de discrecionalidad y ponderación judicial respecto de las consecuencias prácticas de la petición. En palabras de la Corte Suprema:

In sum, although the ATS [ATCA] is a jurisdictional stature creating no new causes of action, the reasonable inference from the historical materials is that the statute was intended to have practical effect the moment it became law. The jurisdictional grant is best read as having been enacted on the understanding that the common law would provide a cause of action for the modest number of international law violations with a potential for personal liability at the time.

We think it is correct, then, to assume that Federal Congress understood that the district courts would recognized private causes of action for certain torts in violation of the law of nations, though we have found no basis to suspect Congress had any examples in mind beyond those torts corresponding to Blackstone's three primary offences: violation of safe conducts, infringement of the rights of ambassadors, and piracy.

$\cdots$

We also agree... that the jurisdiction was originally understood to be available to enforce a small number of international norms that a federal court could properly recognize as within the common law enforceable without further statutory authority.

[T] he judicial power should be exercised on the understanding that the door is still ajar subject to vigilant doorkeeping, and thus open to a narrow class of international norms today".

[W]e are persuaded that federal courts should not recognize private claims under federal common law for violations of any international law norm with less definite content and acceptance among civilized nations 
that the historical paradigms familiar when $\S 1350$ [ATCA] was enacted... This limit upon judicial recognition is generally consistent with the reasoning of many of the courts and judges who faced the issue before it reached this Court. See. Filartiga... ('[F]or purposes of civil liability, the torturer has become-like the pirate and slave trader before him- hostis humani generic, an enemy of all mankind'); Tel-Oren... (Edwards, J., concurring) (suggesting that the 'limits of the section 1350's reach' be defined by 'a handful of heinous actions -each of which violates definable, universal and obligatory norms'); see also In re Estate of Marcos Human Rights Litigation, 25 F.3d 1467, 1475 (C.A.9 1994) ('Actionable violations of international law must be of a norm that is specific, universal and obligatory'). And the determination whether a norm is sufficiently definite to support a cause of action should (and indeed, inevitably must) involve an element of judgment about the practical consequences of making that cause available to litigants in the federal court. ${ }^{41}$

En este punto, además del requisito de la clara definición de las normas internacionales que dan derecho de acción ante los tribunales federales, la Corte Suprema consideró que adicionalmente han de considerarse otros requisitos, por ejemplo, aquellos señalados en el documento de la Comisión Europea (presentado en calidad de Amicus Curiae), respecto de la necesidad del agotamiento previo de los recursos internos. ${ }^{42}$

En general la sentencia en el caso Sosa vs. Alvarez-Machain representó un parteaguas en la dinámica que hasta el momento había tenido la aplicación de la ATCA. En un intento de equilibrar los diferentes intereses en juego, en su fallo salomónico, la corte, por un lado, reconoció que en principio la ley no establece propiamente un derecho de acción abierto sino sólo una competencia jurisdiccional, por el otro, reconoció también la posibilidad de que un número muy limitado de violaciones al derecho internacional puedan ser alegadas en el marco de la ATCA. Por ello, habrá que esperar para conocer los efectos de esta sentencia en la práctica judicial estadounidense y en las estrategias de litigio de los diferentes actores no gubernamentales. Lo cierto es que el caso representó una clara posición favorable a la discrecionalidad judicial en estas materias, por lo que seguramente se seguirán aplicando en un futuro algunas

41 Sosa vs. Alvarez-Machain et al. 542 U.S. 692, 124 S. Ct. 2739, International Law Report, vol. 127, 2005, pp. 787, 792 y 794.

42 Brief for European Commission as Amicus Curiae 24, núm. 54, cit., nota 21; Sosa vs. Alvarez-Machain et al. (124 S. Ct. 2739, 2004). 
de las reglas clásicas de restricción judicial, tales como la doctrina de la cuestión política (the political question doctrine); la regla de la ley posterior (the last-in-time doctrine); el argumento del carácter no autoaplicativo de las normas (the non self-executing thesis); la doctrina del acto de Estado (The Act of State doctrine); el principio de forum non conveniens; el principio de inmunidad soberana de los Estados; y el de la inmunidad diplomática de los jefes de Estado. ${ }^{43}$

\section{COMENTARIO FINAL. JURISDICCIÓN CIVIL E INMUNIDAD DE JURISDICCIÓN}

Una vez expuestos las principales características del ejercicio de la jurisdicción universal en materia civil por los tribunales estadounidenses en aplicación del ATCA es preciso hacer una reflexión adicional respecto del ejercicio de dicha jurisdicción en el contexto de la posición hegemónica de Estados Unidos de América a nivel mundial.

En primer lugar, habría que señalar que, dado que el principio de jurisdicción civil universal establecido en la ATCA no está vinculado con la jurisdicción universal penal, su ejercicio no supone necesariamente el reconocimiento pleno por parte de la legislación estadounidense de los principios fundamentales del derecho internacional, principalmente de la necesidad de protección de los valores básicos del orden internacional expresados en normas de jus cogens y en obligaciones de carácter erga omnes. Al respecto, es conocida la postura del gobierno de Estados Unidos de América respecto del ejercicio de la jurisdicción universal penal por algunos países, así como su posición abiertamente contraria a la Corte Penal Internacional. ${ }^{44}$ Incluso, en los últimos años, a raíz del aumento de las demandas civiles contra empresas transnacionales, el propio gobierno estadounidense también ha criticado la aplicación amplia de la ATCA y ha abogado por la restricción judicial. En este contexto, se ha considerado también que una restricción judicial excesiva, sobre la base de excepciones como la doctrina del acto de Estado, el principio de forum non conveniens o el principio de inmunidad soberana de los Estados

43 Cfr. Lo, Ying-Jen, op. cit., nota 15, p. 49

44 Cfr. Tomuschat, Christian, "Multilateralism in the Age of US Hegemony", en MacDonald, Ronald St. John y Johnston, Douglas (eds.), Towards World Constitutionalism, Leiden-Boston, Martinus Nijhoff Publishers, 2005, pp. 31-75. 
y de los jefes de Estado, pueden derivar en que se aplique la ley sobre indemnización por daños a extranjeros solamente en aquellos casos en que no se afecten los intereses de la política exterior o de la política económica del gobierno estadounidense. Lo que evidentemente implica una merma en la idea misma del derecho a la justicia y a una reparación efectiva.

En segundo lugar, desde la perspectiva de las técnicas de litigio y la búsqueda de acceso a la justicia, si bien es cierto que en algunos casos la ATCA puede ser interpretada como un ejercicio extraterritorial y hegemónico por parte de las autoridades estadounidenses, lo cierto también es que en la actualidad la mayoría de las veces las víctimas de violaciones graves a los derechos humanos no encuentran un foro adecuado para poder no sólo denunciar penalmente los hechos sino también obtener una reparación. En un contexto global en que la responsabilidad del individuo por violaciones a los derechos humanos se encuentra en creciente desarrollo (aunque con limitada eficacia), la ATCA puede contribuir tanto al debate nacional, al interior de Estados Unidos de América, como a la definición de mecanismos de reparación civil adecuados en otros Estados. ${ }^{45}$

En este sentido, la sentencia en el caso Sosa vs. Alvarez-Machain significa un precedente importante que debilita la posición sostenida por la actual administración del presidente George W. Bush, en el sentido de que la vigencia del ATCA impide al gobierno estadounidense perseguir de manera efectiva a los responsables de actos terroristas y amenaza las actividades de sus aliados, como Indonesia o Pakistán, en la denominada "Guerra contra el terrorismo". En consecuencia, la ATCA aunque entrecerrada seguirá siendo también una puerta entreabierta, manteniendo su doble naturaleza de ser, por un lado, un instrumento de hegemonía y,

45 En opinión de Beth van Schaack: "Given the international movement toward individual accountability for rights violations, domestic civil redress provides an important tool in a growing arsenal of mechanisms to enforce international law on the international, regional, and domestic levels. Supranational mechanism will never supplant domestic proceedings, so domestic courts will continue to play a central role in enforcing international law. Victim-centered civil redress has an important role to play in this increasingly integrated regime of international law enforcement". Schaack, "Justice Without Borders: Universal Civil Jurisdiction”, 99 AM. Soc'y Int'l. Proc, p. 123. 
por el otro, un mecanismo último — aunque limitado - contra la impunidad. 46

La verdadera protección integral de los derechos humanos, sin embargo, sólo es posible ahí donde existen recursos judiciales efectivos para la investigación de las violaciones a los derechos humanos, la sanción a los responsables de tales violaciones y la reparación debida a las víctimas. La jurisdicción territorial siempre será preferible ahí donde es realmente efectiva, la jurisdicción universal es un mecanismo excepcional que debe regularse con claridad y ejercerse responsablemente en interés de los valores fundamentales de la comunidad internacional en su conjunto, sea que trate de una instancia penal o civil la que la ejerza.

Por otra parte, la cuestión de la reparación civil por violaciones graves a los derechos humanos ha motivado reflexiones importantes, no sólo respecto de aquellos supuestos de ejercicio de la jurisdicción universal sino también respecto de demandas civiles presentadas contra Estados en donde se ha cuestionado el principio de inmunidad de jurisdicción por violaciones cometidas por un Estado extranjero en el territorio del Estado del foro.

Uno de los casos más significativo de los últimos años (aunque muy cuestionado por doctrina internacional predominante) es el Caso Ferrini vs. República Federal de Alemania resuelto por la Corte de Casación Italiana el 6 de noviembre de 2003 y publicada la sentencia el 11 de marzo de 2004, donde negó la aplicación del principio de inmunidad del Estado de Alemania. En su fallo, la corte consideró que el principio de jurisdicción universal también resulta aplicable en casos civiles tratándose de crímenes internacionales, particularmente, respecto de los crímenes de guerra cometidos por el régimen nazi en territorio italiano. ${ }^{47}$

En sentido similar la Suprema Corte de Grecia, en el Caso de la Prefectura de Votiotia vs. República Federal de Alemania de 4 de mayo de 2000, consideró que un Estado que comete violaciones a las normas de jus

46 Cfr. Flauss, Jean-François, op. cit., nota 1, pp. 386 y ss.

47 Ferrini vs. Federal Republic of Germany (Cass. Sez. Un.5044/04), p. 9. En términos de la corte: "Per la stessa ragione, non si dubita che il principio della università della giurisdizione valga anche per i processi civili che traggono origine da tali reati". Cfr. Focarelli, Carlo, "Denying Foreign State Immunity for Commission of International Crimes: The Ferrini Decision”, 54 ICLQ 2005, pp. 951-958; De Sena, Pasquale y De Vittor, Francesca, "State Immunity and Human Rights: The Italian Supreme Court Decision on the Ferrini Case", EJIL, vol. 16, núm. 1, 2005, pp. 89-112. 
cogens renuncia de manera implícita a su derecho de inmunidad de jurisdicción frente a un tribunal extranjero con competencia sobre el asunto en cuestión. ${ }^{48}$ Esta última posición (the waiver exception) no goza de consenso internacional e incluso la ejecución de la sentencia ha sido imposible tanto en territorio griego como alemán, sin embargo, ha contribuido a abrir el debate. De hecho, en el caso Kalogeropoulou y otros vs. Grecia y Alemania, el Tribunal Europeo de Derechos Humanos desestimó la demanda interpuesta por los beneficiarios del Caso de la Prefectura de Votiotia, confirmando el criterio sostenido en el caso Al-Adsani, en el sentido de que en la actualidad no existe una norma internacional que prescriba que un Estado no goza de inmunidad de jurisdicción respecto de demandas civiles interpuesta en su contra en otro Estado por crímenes contra la humanidad. El Tribunal Europeo señaló, sin embargo, que tal hecho no significa que no pueda desarrollarse una norma internacional en ese sentido. ${ }^{49}$

Estos casos difieren de otros similares presentados en el contexto de la ATCA por diversas razones. La principal por tratarse de hechos cometidos en el territorio del Estado del foro, por lo que no se está en presencia del ejercicio de una jurisdicción extraterritorial propiamente dicha. Aunque en todos ellos se plantea el conflicto entre el principio de inmunidad de jurisdicción y el principio de respeto a los derechos humanos más fundamentales. En el ámbito de la ATCA, uno de los casos más relevantes en que se cuestionó el principio de inmunidad de jurisdicción a raíz de violaciones graves a los derechos humanos, entre otros, fue el caso Princz vs. República Federal de Alemania. ${ }^{50}$ Si bien la sentencia de

48 Prefecture of Voiotia vs. Federal Republic of Germany, Case No. 11/2000 (Areios Pagos, Sup. Ct. of Greece, 4 de mayo de 2000). Cfr. Bankas, Ernest, op. cit., nota 18, p. 271.

49 Kalogeropoulou and others vs. Greece and Germany, ECHR No. 0059021/00, 12 de diciembre de 2002 (Admissibility Judgment), p. 9. En palabras de la corte "The Court does not find it established, however, that there is yet acceptance in international law of the proposition that States are not entitled to immunity in respect of civil claims for damages brought against them in another State for crimes against humanity... This is true at least as regards the current rule of public international law... but does not preclude a development in customary international law in the future".

50 Princz vs. Federal Republic of Germany, 26 F3d 1166. Antes de la Segunda Guerra Mundial, el señor Hugo Princz era una persona judía que vivía con su familia en Eslovaquia, en 1942 fue arrestado y enviado a un campo de concentración junto con su familia, siendo el único sobreviviente al término de la guerra. En 1992 solicitó ante los 
primera instancia de la Corte de Distrito de Columbia desestimó la aplicación del principio de inmunidad soberana, dicha sentencia fue revocada en apelación. ${ }^{51}$ En otros casos, los tribunales estadounidenses han desestimado las demandas civiles en el contexto de la ATCA con base en la ley de inmunidad soberana extranjera (U.S. Foreign Sovereign Immunities Act, FSIA) aplicando la doctrina de los actos de Estado o considerando el asunto no justiciable..$^{52}$ En la gran mayoría de los casos el debate entre violaciones a normas perentorias de derecho internacional (jus cogens) y el principio de inmunidad soberana de los Estados se ha resuelto a favor del segundo. Tal circunstancia no implica necesariamente una valoración sobre la jerarquía entre ambas normas, sino más bien una cuestión de procedimiento, aunque no siempre resulta clara la relación entre tales normas. Mientras las normas de jus cogens involucran cuestiones sustantivas (normas primarias que establecen derechos y obligaciones), el principio de inmunidad de jurisdicción se refiere a normas de procedimiento (secundarias), que definen las competencias de los Estados respecto de determinadas conductas. En palabras de Hazel Fox: "State immunity is a procedural rule going to the jurisdiction of a national court. It does not go to substantive law; it does not contradict a prohibition contained in a jus cogens norm but merely diverts any breach of it to a different method of settlement. Arguably, then, there is no substantive content in the procedural plea of State Immunity upon which a jus cogens mandate can bite". ${ }^{53}$

En este sentido, cuando la inmunidad de jurisdicción resulta aplicable, los jueces del foro no tienen competencia para conocer sobre tales

tribunales estadounidenses la cantidad de 20 millones de dólares por concepto de indemnización y daños punitivos.

51 Afortunadamente para el señor Princz, los gobiernos de Estados Unidos de América y Alemania, a través de negociaciones diplomáticas llegaron a un acuerdo el 19 de septiembre de 1995, donde el gobierno alemán se comprometió a pagar una suma de 2.1 millones de dólares a aquellos ciudadanos estadounidenses que no hubieren sido indemnizados por las restricciones temporales de las leyes alemanas de indemnización a víctimas del holocausto.

52 Por reforma de 1976 a la FSIA, se introdujo una excepción al principio de inmunidad de jurisdicción de los Estados en aquellos casos de ciudadanos estadounidenses víctimas de actos de tortura, ejecuciones extrajudiciales, sabotaje aéreo, o toma de rehenes, siempre que los Estados responsables se encuentren dentro de la lista del secretario de Estado estadounidense como "Estados que apoyan el terrorismo".

53 Fox, Hazel, The Law of State Immunity, Oxford University Press, 2002, p. 525. 
actos. Sin embargo, hasta el momento la práctica internacional no es completamente uniforme respecto del tratamiento que ha de darse en los tribunales de un Estado en aquellos supuestos en que otro Estado, actuando en ejercicio de sus poderes soberanos (acta jure imperi), vulnera alguna norma imperativa. Parece que en tales casos la vía que goza de mayor consenso internacional para una reclamación es la negociación y, en su caso, la protección diplomática.

Lo cierto es que este mecanismo diplomático, la mayoría de las veces, carece de controles respecto de la actuación del Estado que la ejerce $\mathrm{y}$, además, está sujeto a vínculos de nacionalidad efectiva, lo que resulta altamente complejo si se considera que la mayoría de las violaciones graves a los derechos humanos son cometidas por agentes estatales contra sus propios conciudadanos. En todo caso, si bien este tipo de reclamaciones tienen generalmente su origen en una relación privada entre un extranjero y un Estado, con la intervención del Estado de la nacionalidad del extranjero en ejercicio de la protección diplomática, el conflicto se "internacionaliza" y pasa del ámbito privado al de las relaciones internacionales entre Estados. ${ }^{54}$ En consecuencia, las acciones poco diligentes de un Estado que patrocina la causa de su nacional pueden no derivar en una reparación.

Lo cierto es que la vía judicial interna no siempre lleva a mejores resultados, pues generalmente en los casos en que han intervenido los jue-

54 Tradicionalmente, la cuestión de la protección diplomática se situaba en el ámbito de las relaciones entre Estados como sujetos de derecho internacional en ejercicio de su derecho a hacer prevalecer las normas de derecho internacional en la figura de sus nacionales, tal como lo señaló la Corte Permanente de Justicia Internacional en el asunto Mavrommatis (CPJI, "Mavrommatis Palestine Concession", PCIJ Reports 1925, serie A, núm. 5, p. 12). En la actualidad, sin embargo, se considera que un Estado, cuando hace uso de su derecho a ejercer la protección diplomática, lo hace en nombre de su nacional y no para asegurar el respeto de un derecho propio en la persona de éste. Aún el tema está en discusión. Al respecto véanse los diferentes informes de la Comisión de Derecho Internacional en el capítulo relativo a la "Protección Diplomática", en particular, los rendidos en 2004 y 2005, así como el Proyecto de Artículos sobre la Protección Diplomática aprobado por la CDI en primera lectura (2004). De conformidad con artículo 1 del Proyecto, la protección diplomática "consiste en el recurso a la acción diplomática o a otros medios de solución pacífica por un Estado que asume, por derecho propio, la causa de uno de sus nacionales en razón de un perjuicio sufrido por éste resultado de un hecho internacionalmente ilícito de otro Estado". CDI, Report on the Work of its Fifty-sixth Session (3 May to 4 June and 5 July to 6 August 2004), General Assembly Official Records, Fifty-ninth Session, Supplement núm. 10 (A/59/10). 
ces nacionales, haciendo de lado el principio de inmunidad de jurisdicción del Estado, sus sentencias han sido de difícil o imposible ejecución, teniendo que buscar nuevamente la vía diplomática para encontrar una solución aceptable, no siempre accesible. En definitiva, la cuestión de las inmunidades en materia de violaciones graves a los derechos humanos no está del todo resuelta, aunque en los últimos años se ha avanzado considerablemente.

En el ámbito del derecho penal internacional no parece haber duda respecto de la no procedencia del cargo oficial respecto de la responsabilidad internacional de los individuos por la comisión de crímenes internacionales (tal como se refleja en el artículo 27 del Estatuto de la Corte Penal Internacional), así como tampoco de la respuesta que pueda dar la comunidad internacional organizada (por ejemplo, el Consejo de Seguridad de Naciones Unidas) en el supuesto de que un Estado cometa un crimen internacional (por ejemplo, crimen de agresión, crimen de genocidio, etcétera).

Sin embargo, el debate al respecto no ha terminado. La cuestión relativa a la aplicación del principio de inmunidad de jurisdicción de los Estados en situaciones de violaciones graves a los derechos humanos sigue siendo parte de la discusión en la lucha contra la impunidad y el derecho a una reparación. Desde el punto de vista del derecho internacional, el principio de inmunidad de jurisdicción de los Estados no es aplicable cuando la reparación está en manos de la comunidad internacional organizada. Sin embargo, en la mayoría de los casos, tal como lo estima Christian Tomuschat, sería extremadamente peligroso conferir a Estados individuales la facultad de aplicar castigos a otros Estados, más cuando sobre los intereses de la justicia y el derecho a la reparación de las víctimas se sobrepone el interés político y la estrategia hegemónica. ${ }^{55}$

Por todo ello, los jueces nacionales tienen un importante rol que cumplir al momento de valorar y ponderar los diferentes principios fundamentales del derecho internacional y el juego de las inmunidades; el desarrollo que pueda darse en el ámbito nacional será determinante para

55 Cfr. Tomuschat, Christian, "Individual Reparation Claims in Instances of Grave Human Rights Violations: The Position under General International Law", en Randelzhofer, Albrecht y Tomuschat, Christian (eds.), State Responsibility and the individual. Reparation in Instances of Grave Violations of Human Rights, La Haya, Kluwer Law International, 1999. 
la construcción de soluciones de lege ferenda que permitan el equilibrio entre el principio de inmunidad de jurisdicción estatal y el deber de reparación por violaciones graves a los derechos humanos, y, en ello, habrá que valorar la eficacia o no que ha tenido el principio de jurisdicción universal en materia civil. 